БАГДАСАРОВА Рузана Ашотовна - студентка 4-го курса факультета социальных наук и массовых коммуникаций Финансового университета при Правительстве РФ (125993, Россия, г. Москва, ГСП-3, Ленинградский пр-кт, 49; bagdasarova.ruzana@mail.ru)

\title{
ПРАКТИЧЕСКАЯ РЕАЛИЗАЦИЯ ТЕОРИИ КОНСОЦИАТИВНОЙ ДЕМОКРАТИИ А. ЛЕЙПХАРТА НА ПРИМЕРЕ ПОЛИТИЧЕСКИХ СИСТЕМ СОВРЕМЕННЫХ ГОСУДАРСТВ: СОВЕРШЕНСТВОВАНИЕ КОММУНИКАЦИИ
}

\begin{abstract}
Аннотация. В данной статье автор исследует практическое применение теории консоциативной демократии А. Лейпхарта на основе бинарного анализа на примере политических систем Ливана и Швейцарии, а также рассматривает возможности внедрения консоционализма в Российской Федерации. Актуальность темы исследования обусловлена относительной неизвестностью концепции консоциативной демократии в российской политической науке. Между тем сообщественная демократия является эффективной альтернативой многим политическим моделям с точки зрения разрешения конфликтов в современных многосоставных обществах (как западных, так и восточных) и налаживания эффективной коммуникации в условиях идеологического, этнического, религиозного плюрализма.

Ключевые слова: консоциативная демократия, консоционализм, модели демократии, многосоставное общество, политическая система, сегмент общества
\end{abstract}

Проблемное поле исследования. Одной из наиболее важных проблем в современной политической науке является вопрос о разработке эффективной модели взаимодействия власти и общества в условиях многосоставности и плюрализма, затрудняющих коммуникацию различных групп населения внутри одного государства с глубокими сегментарными различиями. Особенно острое внимание данная тема заслуживает в контексте рассмотрения перспектив сохранения дальнейшей государственности в незападных сообществах с целью поиска результативных механизмов налаживания коммуникативного поля и сохранения внутриполитической стабильности. В свою очередь, американский политолог А. Лейпхарт предпринял попытку исследования многосоставных обществ и предложил идею консоциативной (консоциональной, сообщественной) демократии, обращение к которой с целью практического применения описанных в ней характеристик и механизмов поспособствовало бы последовательному развитию современных государств и большей устойчивости политических систем. С учетом территориальной протяженности и многонациональности для России эта тематика является также актуальной. В связи с этим важно рассмотреть возможности внедрения консоционализма в Российской Федерации на примере элементов политических систем других государств.

Tеоретический обзор. В современной демократической теории значительное место занимает работа «Демократия в многосоставных обществах: сравнительное исследование» (1977 г.) американского исследователя голландского происхождения А. Лейпхарта, в которой он описывал консоциативную демократию как некую политическую модель с сегментарным плюрализмом, включающую в себя множество оснований для деления людей на представителей тех или иных групп в многосоставных обществах. Такие различия имеют под собой различную природу: религиозную, языковую, расовую, этническую, 
региональную и пр. [Лейпхарт 1997]. Все группы людей, которые выделяются в многосоставных обществах, определяются на основе данных сегментарных различий.

Многосоставность общества с точки зрения политической науки можно определить через число активных групп интересов, отличающихся по различным параметрам, в т.ч. и по степени институционализации ${ }^{1}$. Политическая и социальная стабильность является ключевой целью данного общества ввиду представительства различных интересов и сложности их согласования. Политико-социальная стабильность, по мнению А. Лейпхарта, включает в себя такие понятия, как общественный порядок, легитимность власти, эффективность политической системы. Важным условием стабильности такой формы демократии является способность политической элиты приходить к консенсусу по многим вопросам (неудачные примеры - Кипр, Малайзия, Бурунди, которые продемонстрировали неготовность общества и элиты к соглашению на основе взаимных уступок).

Автор теории консоционализма выделяет четыре ключевые черты консоциативной демократии как возможной политической системы:

1) участие представителей всех сегментов многосоставного общества в принятии политических решений, осуществление власти большой коалицией политических лидеров, представляющих интересы всех групп населения, доступ всех партий к осуществлению политики в целях достижения социальной стабильности (создание коалиционного правительства);

2) включенность различных сегментов общества в управленческий процесс в целях недопушения захвата власти представителями одного сегмента многосоставного общества;

3) пропорциональность (как представительства, так и распределения бюджетных средств);

4) право вето меньшинства в целях сохранения и укрепления безопасности каждого сегмента общества.

Особенно доступно объясняется логика функционирования консоциативных демократий в многосоставных обществах Западной Европы на основе взаимосвязи таких сообщественных принципов, как консенсус и сотрудничество в целях укрепления безопасности каждой группы. На практике такая модель применяется в случае, если все группы многосоставного общества обладают своей политической структурой и относительной самостоятельностью [Зворыгина 2014]. Данная концепция также предполагает наличие общих идеалов по основным общественным ценностям и целям.

Американские политологи Р. Шэндэлэн и Й. Люстик критиковали консоциативную модель за отсутствие определенности и гибкости используемых в ней понятий [Schendelen 1989; Lustick 1997]. Д.Л. Горовиц отмечает, что консоционализм может привести к усилению межэтнических противоречий, поскольку сотрудничество представителей различных групп зачастую затруднено и конкурентно [Horowitz 2000]. Некоторые ученые считают, что в наше время консоциативная демократия представляет собой не форму государственного устройства или политического режима, а скорее инструменты или же набор методов для принятия решений с целью предупреждения социальных противоречий и политических конфликтов.

Методология и методика исследования. В основе исследования лежит системный подход, дающий возможность рассмотреть объект исследования как

1 Saurugger S. Consociationalism. - Encyclopædia Britannica. URL: https://www.britannica. com/topic/consociationalism (accessed 05.01.2022). 
целостный комплекс элементов, а также культурологический подход, позволяющий понять особенности взаимодействия различных сегментов общества в выбранных для анализа государствах.

Методика исследования базируется на бинарном анализе, предусматривающем исследование двух стран с целью сопоставления относительно непохожих государств в качестве разных моделей, включающих элементы консоциативной демократии. Объектами исследования стали Ливан и Швейцария как одни из самых ярких примеров осуществления тех или иных элементов консоционализма.

Изучая эти страны, можно выделить общее: эти государства имеют сильную социальную основу, которая может влиять как на законотворческий процесс, так и на реализацию политических решений. Вместе с тем размежевание данных многосоставных обществ на сегменты может носить как религиозный (Ливан), так и языковой и этнический (Швейцария) характер. Более того, различный ход становления государств также по-разному влияет на отношения центра и сегментов общества (Ливан - унитарное государство, государство Ближнего Востока; Швейцария - федерация (номинально - конфедерация), государство Западной Европы). Обе страны по различным параметрам демократических индексов относятся либо к гибридному режиму (Ливан), либо к странам, показывающим устойчивый пример демократического правления (Швейцария). В дальнейшем возможно расширение сферы анализа и распространение его и на другие страны.

Результаты. Ливанская Республика. Самым приближенным вариантом консоциативной демократии с точки зрения ее устойчивости может являться Ливан. Здесь так или иначе к политической власти допущены представители всех конфессий. Данная модель государственного устройства получила название «ливанский конфессионализм». Согласно политической модели, существующей в Ливане, президентом страны может стать только христианин-маронит, премьер-министром - мусульманин-суннит, спикером Национальной ассамблеи Ливана (парламент) должен быть мусульманин-шиит; во всех органах власти места должны быть разделены пропорционально между христианами и мусульманами. Следовательно, это показывает, что борьба между политическими партиями идет в пределах определенных закрепленных религиозных квот. Процентное соотношение последователей основных религий на территории Ливана приведены в табл. 1.

Таблица 1

Религия в Ливане

\begin{tabular}{|c|c|c|c|c|}
\hline \multicolumn{2}{|c|}{$\begin{array}{l}\text { Мусульмане (сунниты + } \\
\text { шииты) - 63,1\% }\end{array}$} & Христиане - 32,4\% & \multirow{3}{*}{$\begin{array}{l}\text { Друзы } \\
-4,5 \%\end{array}$} & \multirow{3}{*}{$\begin{array}{l}\text { Иудаисты, } \\
\text { бахаисты, } \\
\text { буддисты и } \\
\text { индуисты } \\
\text { (крайне } \\
\text { небольшое } \\
\text { число) }\end{array}$} \\
\hline $\begin{array}{l}\text { Сунниты } \\
-31,9 \%\end{array}$ & $\begin{array}{l}\text { Шииты } \\
-31,2 \%\end{array}$ & \multirow{2}{*}{$\begin{array}{l}\text { Крупнейшая } \\
\text { христианская } \\
\text { группа - } \\
\text { католики-марониты }\end{array}$} & & \\
\hline \multicolumn{2}{|c|}{ 4,7\% - алавиты и исмаилиты } & & & \\
\hline
\end{tabular}

Источник: составлено автором по данным CIA World Factbook за 2020 г. URL: https://www. cia.gov/the-world-factbook/countries/lebanon/ (accessed 05.01.2022).

Согласно интегральному Индексу демократии, разработанному британской компанией The Economist Intelligence Unit (EIU), политическая система Ливана относится к гибридной - имеющей как демократические, так и авторитар- 
ные черты (общий балл составил 4,16, 108-е место). Данный рейтинг определенно несколько тенденциозен, однако Индекс демократии рассчитывается по широкой сетке различных параметров и показателей, что позволяет изучить глубину функционирования элементов конкретной модели реализации консоционализма. Представляются следующие данные по 5 категориям по Ливану за 2020 г.: электоральный процесс и плюрализм - 3,50; функционирование государства $-1,50$; политическое участие $-6,67$; политическая культура $-5,00$; гражданские свободы - 4,12. С 2006 по 2020 г. наблюдается плавное снижение различных компонентов индекса (общий балл снизился с 5,82 до 4,16); страна перешла из категории «несовершенных» демократий в категорию гибридных режимов ${ }^{1}$. Можно заметить, что, несмотря на высокий уровень политического участия $(6,67)$ и политической культуры $(5,00)$, наблюдается одновременно низкий показатель деятельности правительства $(1,50)$. Это указывает на то, что политическое участие и широкая представленность различных сегментов в процессе управления (ливанский пример консоционализма - конфессионализм) не приводит к развитию гражданского общества и совершенствованию управленческого процесса, направленного на развитие государственных институтов. Подобное коммуникативное взаимодействие можно назвать малоэффективным, несмотря на практическую реализацию черт разработанной А. Лейпхартом модели. Необходимо понимать также и динамичность соотношения сегментов общества в государственном управлении, поскольку это также усугубляет кризисные ситуации (пример Ливана - увеличение доли мусульман и связанные с этим противоречия в распределении государственных постов).

С ростом информационной открытости и социальной мобильности, демографическими изменениями на ливанские социальные отношения также оказывает влияние и глобализация. Однако ливанская демократия до сих пор сохраняет выбранную консоциативную модель, которой необходимо стать более гибкой, развивая внутренний реформаторский потенциал во избежание кризисных ситуаций [Сарабьев 2019]. Поскольку политические элиты играют ключевую роль, необходим высокий уровень их ответственности.

Швейцарская Конфедерация. Рассматривая элементы консоциативной демократии в политической системе Швейцарии, необходимо отметить, что страна занимает особое место внутри романской и германской Европы, что имеет свое отражение в наличии четырех языковых и культурных регионов. Официальными языками на территории государства признаются немецкий, итальянский, французский, а также романшский (архаичный романский) языки.

Основное место в территориально-административном устройстве Швейцарии занимают кантоны. Швейцария, номинально являясь конфедерацией, а фактически - федеративной республикой, состоит из 26 кантонов (включая полукантоны), причем многие города-государства имеют разные названия в зависимости от языка. Каждый кантон имеет собственные атрибуты власти, собственную конституцию и законодательство. Семнадцать кантонов исключительно немецкоязычные, четыре - франкоязычные и лишь один - италоязычный (Тичино); в четырех кантонах немецкий язык существует вместе с французским (Берн, Фрибург, Валлис) и итальянским (Граубюнден).

Правительство Швейцарии - Федеральный совет, являясь фактически коллективной главой государства, состоит из следующих представителей: трое

${ }^{1}$ EIU Democracy Index. URL: https://www.eiu.com/n/ (accessed 05.01.2022). 
немецкоязычных членов, двое франкоязычных и двое италоязычных членов. Государственную должность можно занять, лишь зная все официальные языки. В Швейцарии также активно применяется прямая демократия, например посредством референдума. Исторически сложилось, что коллективный Федеральный совет Швейцарии воспринимается и на национальном, и на международном уровне как стабильный и компетентный орган власти [Дубровина 2019]. При данной системе Швейцарии удается избегать острых политических конфликтов.

Согласно интегральному Индексу демократии, политическая система Швейцарии относится к устойчивой демократии (общий балл составляет 8,83 ; страна занимает 12-е место). По данным, полученным в результате исследования, Швейцария в 2020 г. получила следующие оценки: электоральный процесс и плюрализм - 9,58; функционирование государства $-8,57$; политическое участие - 7,78; политическая культура - 9,38, гражданские свободы - 8,82. С 2006 по 2019 г. наблюдается устойчивость швейцарской политической системы: страна получает стабильные позиции с общим баллом в 9,03/9,09 со снижением оценки в 2020 г. Это говорит о том, что швейцарские власти выработали эффективную модель взаимодействия власти и общества с высоким уровнем политической культуры и политического участия, уважением плюрализма и реализацией гражданских свобод.

Рассматривая критику теории консоциативной демократии на примере Швейцарии, исследователи отмечают, что данное государство никогда не было разделенным на сегменты обществом, а языковые общности, существующие на территории страны, абсолютно не конфликтны и однородны.

Британский политолог Б. Бэрри отмечает, что ввиду того что правительство Швейцарии состоит всего лишь из 7 членов, они вовсе не представляют интересы языковых и культурных общностей. Более того, по мнению исследователя, все ключевые решения принимаются не правительством, а посредством референдума [Barry 1975]. Многие политические исследователи поддерживают мнение нидерландского политолога Х. Даалдэра, что вообще непонятно, применим ли к Швейцарии консоционализм: несмотря на то что некоторые элементы консоциативной демократии присутствуют на уровне политических элит, сильное сегментарное деление на территории страны не существует [Daalder 1974].

Российская Федерация. Говоря о переносе зарубежного опыта консоциативной демократии на российскую государственность, необходимо учитывать особенности Российской Федерации. В первую очередь, социологические исследования показывают, что граждане РФ не обладают высоким уровнем политической и правовой культуры (в т.ч. высок и уровень абсентеизма) ${ }^{1}$. У россиян нет надэтнической идентичности, которая бы способствовала эффективному принятию политических решений в интересах государства. С точки зрения политической науки теория консоционализма подходит для России, однако с учетом разнородного социокультурного компонента.

Согласно интегральному Индексу демократии, политическая система России относится к авторитарному режиму (общий балл составляет 3,31 ; РФ занимает 124-е место в рейтинге). За 2020 г. страна набрала следующие оценки по разработанным исследователями параметрам Индекса демократии: электоральный процесс и плюрализм - 2,17; функционирование государства (деятельность правительства) - 2,14; политическое участие $-5,00$; политическая культура

1 Явка на выборы - 2021: аналитический обзор ВЦИОМ. Август 2021. Доступ: https:// wciom.ru/analytical-reviews/analiticheskii-obzor/javka-na-vybory-2021 (проверено 05.01.2022). 
- 3,13; гражданские свободы - 4,12. С 2006 по 2018 г. отмечается резкое ухудшение позиций страны (с 5,02 до 2,94), однако с 2018 по 2020 г. общий балл растет до 3,31. Несмотря на то что при составлении рейтинга очевидна роль человеческого фактора (индекс рассчитывается на основе 60 показателей по 5 выделенным категориям по результатам экспертных оценок), необходим пересмотр российской модели политического взаимодействия с учетом описанных выше практик, поскольку сегментарные различия внутри российского общества крайне сильны.

На рис. 1 отражена динамика изменения Индекса демократии в Ливане, Швейцарии и России с 2006 по 2020 г. по данным EIU.

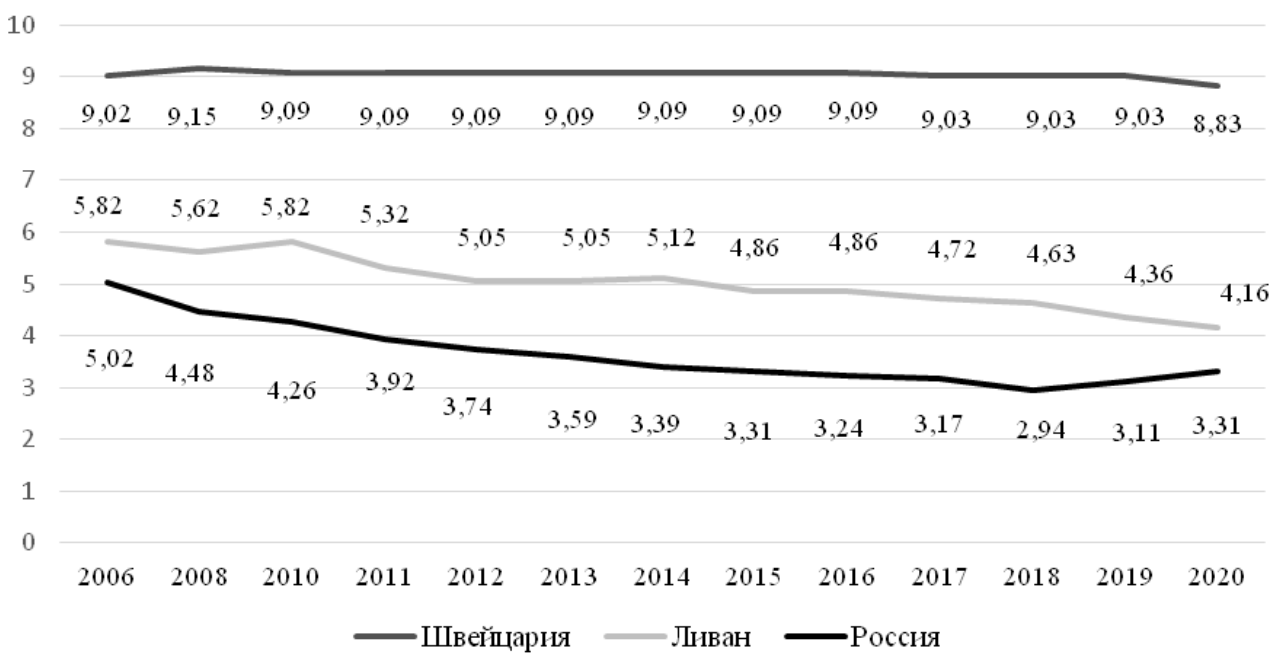

Источник: составлено автором по данным EIU. Доступ: https://www.eiu.com/n/ (accessed 05.01.2022).

Рисунок 1. Динамика изменения Индекса демократии по данным EIU (20062020 гг.)

Проблемы внедрения модели консоциативной демократии в РФ обусловлены следующими причинами.

1. Сложность идентификации сложившихся этносов на территории России. Например, население на территории Северного Кавказа идентифицирует себя с помощью определенного клана, рода [Зворыгина 2014]. Из этого следует вопрос, насколько допустимо делегирование представителей от всех групп в политику и стоит ли сохранять во власти сложившиеся традиционные отношения?

2. Применение модели консоционализма к российскому опыту искусственно сокращает социальную мобильность населения, поскольку рекрутирование в элиту также происходит по искусственному принципу.

3. Установление определенной квоты в представительных органах власти означает нарушение Конституции РФ - Основного закона государства, по которому все равны перед законом.

4. Низкий уровень политической культуры граждан РФ также ведет к борьбе за доминирование определенного сегмента. 
5. Неравномерность развития субъектов РФ и территориальная протяженность определяют сложность представительства [Малеев 2021].

6. Выстроенная система вертикали власти в отношениях с региональной властью затрудняет внедрение элементов сообщественной демократии и допуск представителей различных сегментов общества к власти.

7. Если представители разных конфессиональных групп принадлежат также к разным этническим и иным группам, возникает сложность рекрутирования политической элиты, и др.

В связи с наличием данных проблем пока сложно говорить о применимости консоциативной модели демократии к российской политической системе и о конкретных перспективах ее реализации, хотя определенные элементы минимально присутствуют (например, при выборах в Государственную думу РФ половина депутатов ГД ФС РФ (225 чел.) избираются по федеральному избирательному округу пропорционально числу голосов избирателей как некий элемент пропорциональности представительства).

Bыводы. Подводя итоги, можно сказать, что исследование элементов консоциативной демократии в политических системах Ливана, Швейцарии и России показало, что важнейшим элементом внедрения консоционализма должны стать возможность и способность согласования интересов и разрешения разногласий и конфликтов, связанных с различными проявлениями плюрализма. Практики консоциативной демократии способствуют гибкому сосуществованию сегментов общества, различающихся по самым разным основаниям в рамках одного многосоставного государства. Консоционализм уникален в каждой политической системе. Ни в одной политической системе одинаковых консоциативных сообществ просто не существует, как и различно становление демократической системы на протяжении последних десятилетий.

Исследование продемонстрировало, что внедрение консоционализма в политическую систему РФ пока затруднено. У исследователей также возникают вопросы по моделям консоциативной демократии в других политических системах. В заключение можно сделать вывод, что построение консоциативной демократии по модели А. Лейпхарта возможно только в тех государствах, в которых, наряду с многосоставностью, существует определенное число активных групп интересов, способных проводить самостоятельную политику. Участие представителей всех сегментов общества, а также их политика должны служить единой цели - достижению и сохранению политической и социальной стабильности. Современные формы консоциации могут служить эффективным инструментом для построения демократического плюрального общества.

\section{Список литературы}

Дубровина О.Ю. 2019. Швейцария: распределение полномочий между Конфедерацией и кантонами в сфере международных отношений. Современная Европа. № 1(87). С. 70-80.

Зворыгина М.А. 2014. Российский федерализм и зарубежный опыт консоциальной демократии. - Тренды и управление. № 1. С. 14-20.

Лейпхарт А. 1997. Демократия в многосоставных обществах: сравнительное исследование (пер. с англ. Б.И. Макаренко). М.: Аспект Пресс. 290 с.

Малеев В.В. 2021. Фактор доверия в формуле построения консоциативной демократии в многосоставных обществах. - Власть. Т. 29. № 3. С. 316-319.

Сарабьев А.В. 2019. Ливан: обыкновенная «консоциональная демократия» в региональном контексте. - Вестник МГИМО Университета. Т. 12. № 4. C. $89-112$. 
Barry B. 1975. Political Accommodation and Consociational Democracy. - British Journal of Political Science. Vol. 5. Is. 4. P. 477-505.

Daalder H. 1974. The Consociational Democracy Theme. - World Politics. Vol. 26. Is. 4. P. 604-621.

Horowitz D.L. 2000. Ethnic Groups in Conflict. Berkeley, Calif.; London: University of California Press. 697 p.

Lustick I.S. 1997. Lijphart, Lakatos, and Consociationalism. - World Politics. Vol. 50. Is. 1. 50 th Anniv. Special Issue. Oct. P. 88-117.

Schendelen V. 1989. The Views of Arend Lijharp and Collected Critisims. - Acta Politica. Vol. 19. Is. 1. P. 19-49.

BAGDASAROVA Ruzana Ashotovna, $4^{\text {th }}$ year student of the Faculty of Social Sciences and Mass Communications, Financial University under the Government of the Russian Federation (49 Leningradsky Ave, GSP-3, Moscow, Russia, 125993; bagdasarova.ruzana@mail.ru)

\section{PRACTICAL IMPLEMENTATION OF A. LIJPHART'S THEORY OF CONSOCIATIONAL DEMOCRACY ON THE EXAMPLE OF POLITICAL SYSTEMS OF MODERN STATES: IMPROVEMENT OF COMMUNICATION}

\footnotetext{
Abstract. In this article, the author explores the practical application of A. Lijphart's theory of consociational democracy based on binary analysis of the political systems of Lebanon and Switzerland, and examines the possibilities of introducing consociationalism in the Russian Federation. The relevance of the research topic is due to the relative obscurity of the concept of consociational democracy in Russian political science. Meanwhile, consociationalism is an effective alternative to many political models in terms of conflict resolution in modern multi-component societies (both western and eastern) and establishing effective communication in conditions of ideological, ethnic, religious pluralism.

Keywords: consociational democracy, consociationalism, models of democracy, multi-component society, political system, segment of society
} 